\title{
The Explanation Effect Of Fundamental Dimension On Junior School Students' Self-esteem
}

\author{
Li Xuejiao Bi Chongzeng \\ School of Psychology, Southwest University, Chongqing, China, 400715
}

\begin{abstract}
In order to explore the explanation effect of fundamental dimension on junior school students' self-esteem and try to figure out which kind of traits has more influence. We used Rosenberg Self-esteem Scale and an adjective list that involved vocabularies which were categorized into agency and communion to investigate 380 junior school students. The results showed that the self-esteem was influenced by both communion and agency, but dominated by agency.
\end{abstract}

Keywords: fundamental dimension, agency, communion, self-esteem

\section{Introduction}

The adolescence is of great importance to one's growth. During this period, individuals get a high speed development in both physical and mental aspects, so is the self-conscious. However, as psychosocial development theory (Erikson, 1966) has suggested, individuals in adolescence period may face the identity crisis. In order to solve the crisis, adolescence has to establish self-identity, which is a process along with the development of their whole life.

Teenagers may do something intentionally or unintentionally to deal with the identity crisis. Some try to make success and achieve their goals, some make contact with others and intend to be accepted as an important member of groups. William James(1890) proposed that "self-esteem $=$ success/pretention, is a certain average tone of self-feeling which each one of us carries about him and which is independent of the objective reasons we may have for satisfaction and discontent." Put it in another way, it suggested that individuals' behaviors and the following consequences might have influence on people's self-esteem. However, Leary (2000) proposed that self-esteem developed to help people monitor their social acceptance. The experience of low or high self-esteem severs as a signal to people of the extent to which they are succeeding in establishing social connection with others or at risk for social devaluation and rejection (Anthony, Wood, \& Holmes, 2007; Leary, 2003). Self-esteem serves as a sociometer, driving people to take some actions to reduce the possibility of being excluded and rejected. From this perspective, making connection with others and being accepted by group are of great importance to individuals and may have significant influence on self-esteem.

No matter which kind of the behavior is, making success and chasing achievement or making connecting with others and trying to be accepted by group, it could be concluded into the concept of fundamental dimensions. Bank (1966) came up with the fundamental dimension to characterize two fundamental modalities in the existence of living forms, agency for the existence of an organism as an individual, and communion for the participation for the individual in some lager organism of which the individual is a part. Agency is related to self-focus and distinction with others, which represents strivings expansion and elevation that surface as efforts to chase social dominance, including following positive traits such as active, clever, capable and some negative traits such as dump, passive, dominant; communion, however, pays more attention on other people, which represents strivings for contacting with others and being accepted by a group as an important member, including following positive traits such as warm, caring, kind and some negative traits such as cool, dishonest and so on (Bakan, 1966; Cuddy et al., 2008; Fiske, Cuddy, Glick, \& Xu, 2002; Wojciszke, 2005).

Many recent studies on fundamental dimension have found that communion takes priority. Ybarra, Chan and Park (2001) found that people respond faster to communion dimension stimuli than to agency dimension stimuli. Willis and Todorov (2006) 
conducted an experiment using materials with implied meaning of agency and communion. They asked participants to recognize which kind the photo belongs to, communion or agency. It turned out that even within every short expose, people still can make more correct recognitions on communal materials than agentic materials. Abele and Bruckmüller (2011) suggested that communal information may be processed preferentially on many stages of information processing such as information gathering, classifying, and recognizing and some other procedure; Even in different cultural backgrounds, participants would pay more attention on others' communal traits and show more emphasis on communal information when they evaluate and judge others.

Furthermore, Abele and Wojciszke (2007) found that in the process of evaluating and judging themselves and others, people get better scores on communal traits than on agentic traits. But they evaluate themselves with higher scores than others referring to agentic traits.

In spite of the fact that agency and communion coexist in individuals' personality, the levels of these two fundamental dimensions are different. Some people get high level of positive communal traits but low positive agentic traits, and some people may be opposite. The question is which kind of traits make the major contribution to self-esteem, the communal traits related to interpersonal and social relationship or the agentic traits related to goal achievement and accomplishment?

Cognitive ability of adolescence is improving but still immature. In this period, the promotion of competent takes priority and their self-explorations grow deeper but self-evaluations are still unstable, thus connection with others and sociality become a crucial way to know themselves and the world. Hence, it is meaningful to explore the influence of fundamental dimension on their self-esteem.

\section{Method}

\subsection{Participants}

380 junior school students participated in the study, 164 females and 216 males, the average age was 15.14 years $(S D=1.11)$.

\subsection{Materials}

\subsubsection{Rosenberg Self-Esteem Scale.}

The scale was developed by Rosenberg. It included ten items and the response was collected on 4-points scales ranging from 1 to 4 . The $\alpha$ of this instrument in current study was 0.741 .

\subsubsection{Adjectives List of Traits}

The word list was established by Abele and Bruckmüller (2011). We translated and rated the words, 38 participants, got 4 categories, 12 words each (3 were deleted from the original list). The valence characterize of the agentic and the communal content like the original. Agency words were rated as higher in agentic content $(M=3.83, S D=.61)$ than communion words $(M=2.43, S D=.92)$ and communion words were rated as higher in communal content $(M=4.50, S D=.75)$ than agentic words $(M=3.17, S D=.88), t \mathrm{~s}(37)>9.54 ; p \mathrm{~s}<.001$. [The scale 0 6]. Agency words $(M=1.87, S D=.41)$ were rated above the scale mean [0] on agency, $t(37)=28.03$, $p<.001$, and communion words $(M=1.87, S D=.47)$ were also rated above the scale mean [0] on communion, $t(37)$ $=24.52, p<.001$. Agency words (positive: $M=2.10$, $S D=.43$, negative: $M=-1.64, S D=.46$ ) and communion words (positive: $M=2.13, S D=.50$, negative: $M=-1.61$, $S D=0.58$ ) were rated as equally favorable, both $t \mathrm{~s}<0.66$, $p \mathrm{~s}>0.5$, and there was also no content dimension by valence interaction, $F<0.1, p>.05$. [The scale $-3 \sim+3$ ]

\section{Procedure}

The questionnaire were filled out in classrooms, and after completing the survey, the participants were debriefed and thanked.

\section{Results}

\subsection{The prediction of agency on self-esteem}

Self-esteem was severed as independent variable and both positive agentic traits and negative agentic traits are dependent variables. The results showed that both positive agentic traits $(t(380)=7.69, p<0.001)$ and negative agentic traits $(t(380)=-7.62, p<0.001)$ had an significant effect. When take agency dimension into consideration only, the agentic traits make a significant contribution to self-esteem, people who have a higher level of positive traits, may have higher level of 
self-esteem, in contrast, people who got a higher level of negative agentic traits, may have lower lever of self-esteem.

Table 1. The Prediction of Agency on Self-esteem

\begin{tabular}{cccc}
\hline Predictor & $B$ & $t$ & Sig \\
\hline Positive agentic traits & 0.35 & 7.69 & 0.000 \\
Negative agentic traits & -0.35 & -7.62 & 0.000 \\
\hline
\end{tabular}

Note: $R^{2}=0.32, F<105.017, p<0.001$

4.2. The prediction of communion on self-esteem

Self-esteem served as an independent variable, positive communal traits and negative communal traits were conducted into a regression equation. The results showed both positive communal traits $(t(380)=7.35$, $p<0.001)$ and negative communal traits $(t(380)=-4.18$, $p<0.001$ )made a significant contribution to self-esteem. As the results shows, when take communion dimension into consideration only, communal traits made a significant contribution to self-esteem. People with higher level of positive communal traits may get higher self-esteem and, who with higher level of negative communal trait, may have lower self-esteem.

Table 2. The Prediction of Communion on Self-esteem

\begin{tabular}{llcc}
\hline Predictor & $\beta$ & $t$ & \multicolumn{1}{c}{ Sig } \\
\hline Positive communal traits & 0.36 & 7.35 & 0.000 \\
Negative communal traits & -0.20 & -4.18 & 0.000 \\
\hline
\end{tabular}

Note: $R^{2}=0.24, F<63.10, p<0.001$.

4.3. The prediction of two dimensions on self-esteem

In order to assess the effects of the predictors fundamental dimension-on self-esteem, we took agency and communion (including negative traits and negative traits) into consideration at the same time. The results showed that when both dimensions conducted into regression equation, only agency dimension made a significant contribution to the self-esteem (positive agentic traits: $t(380)=5.16, p<0.001$; negative agentic traits : $t(380)=-4.24, p<0.001)$.

Table 3. Prediction of Two Dimensions on Self-esteem

\begin{tabular}{lccl}
\hline Predictor & $\beta$ & $t$ & Sig \\
\hline Positive agentic traits & 0.30 & 5.16 & 0.000 \\
Negative agentic traits & -0.28 & -4.24 & 0.000 \\
Positive communal traits & 0.10 & 1.64 & 0.103 \\
Negative communal traits & -0.05 & -.78 & 0.435 \\
\hline
\end{tabular}

Note: $R^{2}=0.33, \quad F<56.50, p<0.001$.

\section{Discussion}

The present study was to investigate the contribution of fundamental dimension to junior high school students' self-esteem. We investigated 380 students' self-esteem and self-evaluation with Rosenberg self-esteem scale and an adjective list of traits. The analysis of regressions showed that both agency and communion were of great importance in predicting one's self-esteem separately. However, compared to communal dimension, agentic dimension played a much more important role, therefore self-esteem was dominated by agency rather than communion.

Experience of success is vital to adolescence and has crucial influence on development. The nature of agency is self-profitability, that is, agentic traits are much more related to the traits-possessor, especially when people are trying to make success and chase achievement. Individuals would benefit from the positive agentive traits and get hurt from negative agentic traits. Evolutionary psychology indicated that when encountering with others, people must determine, first, the intension of the other person, second, their ability to act on these intentions (Fiske, Cuddy, \& Glick, 2007). The determinations are based on the evaluations and judgments of other people's communion and agency. However, when the evaluation and judgment turn to people themselves, the focus would consequentially turn to their own ability. In this condition, people may pay attention to their agentic traits more related to goal achieve and success. A double perspective model put forward by Wojciszke and his colleagues also suggested that generally social behavior involves two perspectives-one from the agent who perform the act and another from the recipient whom the action is directed and on the receiving end of action (Wojciszke, Baryla, Parzuchowski, Szymkow, \& Abele, 2011). The mission of agent is to make the behavior done, and, for recipient, the mission is to understand of what is being done and focus on avoiding harms or acquiring benefits which bought by the behavior. So, when people play the role of agent, it is important to put all the intelligence, smartness, persistence and other positive agentic trait to use to make sure that the action would be done and not failure. Studies on gender role and self-worth also 
suggested that masculine-related traits which were expressed in terms agency traits made a significant contribution to self-worth (Bi C, Xiao Y, Li X, Di X, Cai Z,\& Alexander ,2013; Bi, C., Ybarra, O., \& Zhao, Y. 2013).

When it comes to communal dimension, the effect was significant when predicting self-esteem all by communion itself. Both positive communal traits and negative communal traits make significant contributions to self-esteem. In contrast with agentic traits which are self-profitability (Peters, 1992), communal traits are other-profitability traits which are directly beneficial for other people when positive and directly harmful when negative. People with kind, caring friendly, honest and some other positive communal traits are more likely to make connection with others and be accepted by a group. Peer relations, classmate relations and teacher student relations are vital to adolescence. Denissen and his collogues proposed that the quality and quantity of individuals' social relationships have profound influence on one's self-esteem (Denissen, Penke, Schmitt, \& Aken, 2008). For junior high school students, making an improvement and development on communal aspect is not only a premise of forming well interpersonal and social relationships, but also a demand from society even in different cultural backgrounds, that is, social member should have honest, kind, and trusted traits. This kind of request then gradually become a social standard and influence people's self-esteem.

Self-esteem can be influenced by judgments from other people and social acceptance or rejection. Communal dimension serves as the first object when people are observed by others. It plays an important role in the formation of self-esteem. However, self-esteem is much more dynamic stabile and to a large extent, determined by how people view themselves and related to one's intelligence, competence and achievements. Evaluations and judgments from others that may impact by communal dimension would change under different circumstances. Individuals cannot form a healthy self-esteem based on unstable evaluations and judgments. However, on the other hand, traits from agentic dimension such as competent, persistence and active are stable and controllable therefore are essential to the formation of healthy self-esteem. In aspect of communal dimension, the standard that social member should be a good one and do no harm to group is equal to every member. In order to attain the standard, people would express more communal traits and avoid negative traits. Under this circumstance, there would be few distinctions between people. However, traits of agentic dimension, especially the positive traits, are regarded as more characteristic and hard to pretend. So individuals can make clear social distinction on this dimension. To a certain extent, it is reasonable to suggest that individual obey the social standard in order to be accepted by others and groups in aspect of communion. Then, they would swing to pay more attention to agentic dimension. Overall, both agency and communion are vital to junior high school students. However, in comparison with communion, agency is much more important and occupying the dominated position. The educators of junior high school should focus on students' development in comprehensive and harmonious way and put highlights on both agency and communion.

\section{Conclusion}

The present study showed that both agentic dimension and communal dimension had contribution to individual's self-esteem. Along with goal achieved and succeed, being accepted by others and groups is of great importance to self-esteem.

In comparison with the influence of communion on self-esteem, agency is more important. Junior school students' Self-esteem is dominated by their agentic traits.

\section{Reference}

[1]. Abele, A. E., \& Bruckmüller, S. (2011). The bigger one of the "Big Two"? Preferential processing of communal information. Journal of Experimental Social Psychology, 47, 935-948.

[2]. Bi, C., Xiao, Y., Li, X., Di, X., Cai, Z., \& Alexander .U (2013). Is Androgyny Better than Masculinity? : The Influence of Gender Roles on College Students' self-worth. Journal of Southwest China Normal University: Natural Science Edition, 38(4) 
[3]. Bi, C., Ybarra, O., \& Zhao, Y. (2013). Accentuating Your Masculine Side. Social Psychology, 44(2), 103-108.

[4]. Abele, A. E., \& Wojciszke, B. (2007). Agency and communion from the perspective of self versus others. Journal of Personality and Social Psychology, 93(5), 751.

[5]. Anthony, D. B., Holmes, J. G., \& Wood, J. V. (2007). Social acceptance and self-esteem: tuning the sociometer to interpersonal value. Journal of personality and social psychology, 92(6), 1024.

[6]. Bakan, D. (1966). The duality of human existence: An essay on psychology and religion.

[7]. Cuddy, A. J. C., Fiske, S. T., \& Glick, P. (2008). Warmth and competence as universal dimensions of social perception: The stereotype content model and the BIAS map. Advances in experimental social psychology, 40, 61-149.

[8]. Denissen, J. J. A., Penke, L., Schmitt, D. P., \& van Aken, M. A. G. (2008). Self-esteem reactions to social interactions: evidence for sociometer mechanisms across days, people, and nations. Journal of Personality and Social Psychology, 95(1), 181

[9]. Erikson, E. H. (1966). Eight ages of man. International Journal of Psychiatry.

[10]. Fiske, S. T., Cuddy, A. J. C., \& Glick, P. (2007). Universal dimensions of social cognition: Warmth and competence. Trends in cognitive sciences, 11(2), 77-83.

[11]. Fiske, S. T., Cuddy, A. J. C., Glick, P., \& Xu, J. (2002). A model of (often mixed) stereotype content: competence and warmth respectively follow from perceived status and competition. Journal of Personality and Social Psychology, 82(6), 878

[12]. William, J. (1890). The principles of psychology. Harvard UP, Cambridge, MA.

[13]. Leary, M. R., \& Baumeister, R. F. (2000). The nature and function of self-esteem: Sociometer theory. Advances in experimental social psychology, 32, 1-62.

[14]. Leary, M. R. (2003). Individual Differences in Self-Esteem: A Review and Thearetical integrations. Handbook of self and identity, 401.
[15]. Peeters, G. (1992). Evaluative meanings of adjectives invitro and in context-some theoretical implications and practical consequences of positive-negative asymmetry and behavioral-adaptive concepts of evaluation. Psychological Belgica, 32(2), 211-231.

[16]. Rosenberg, M. (1965). Society and the adolescent self-image. Princeton, NJ: Princeton University Press.

[17]. Tausch, N., Kenworthy, J. B., \& Hewstone, M. (2007). The confirmability and disconfirmability of trait concepts revisited: Does content matter? Journal of Personality and Social Psychology, 92(3), 542

[18]. Willis, J., \& Todorov, A. (2006). First Impressions Making Up Your Mind after a 100-Ms Exposure to a Face. Psychological science, 17(7), 592-598.

[19]. Wojciszke, B. (2005). Morality and competence in person-and self-perception. European review of social psychology, 16(1), 155-188.

[20]. Wojciszke, B., \& Abele, A. E. (2008). The primacy of communion over agency and its reversals in evaluations. European Journal of Social Psychology, 38(7), 1139-1147.

[21]. Wojciszke, B., Baryla, W., Parzuchowski, M., Szymkow, A., \& Abele, A. E. (2011). Self - esteem is dominated by agentic over communal information. European Journal of Social Psychology, 41(5), 617-627.

[22]. Ybarra, O., Chan, E., \& Park, D. (2001). Young and old adults' concerns about morality and competence. Motivation and Emotion, 25(2), 85-100. 